\title{
Of Lotteries Lost and Partnerships Forged: The Perils and Promises of Patient Ethics
}

\author{
GRIFFIN TROTTER
}

In fall 2002, Paul Ellwood's Jackson Hole Group proposed "Heroic Pathways" a healthcare reform concept that includes (1) a voluntary system of portable, personal electronic medical records owned by patients and (2) a health information pathway that is managed by patients and clinicians. This proposal, like so much of the innovative thinking in healthcare policy, is premised on the conviction that informed patients will drive healthcare changes in the near future.

Everywhere one turns (except perhaps in the bioethics literature) the idea that patients should have more information, more choices, and more responsibility for overseeing their own healthcare is rife. And several trends suggest that the idea is being rapidly translated into new healthcare habits. First, patients have started reading their own medical records. A Wall Street Journal article documenting patients' use of personal electronic medical records ${ }^{2}$ reports that a Marlton, New Jersey, woman was "able to forestall the possible onset of pneumonia" in her father by examining his online medical records and notifying his Lake Scranton, Pennsylvania, physician that she had seen a temperature spike. $^{3}$ The same article tells of a 55-year-old patient afflicted by CHF who made salient dietary changes after logging on and noticing that he had an elevated sodium level.

Second, patients are starting to read the medical literature-and they are bringing their newfound knowledge into the physician's office. ${ }^{4}$ For fees ranging from $\$ 195$ to $\$ 550$, medical search services will provide patients with detailed reports on the latest treatments, experts, and research pertaining to a given health concern. ${ }^{5}$ Several academic institutions are even offering a "minimedical school" curriculum for patients who want to be at the cutting edge.

Third, patients are starting to make their own medical purchasing decisionssometimes apart from experts' advice or health plans' coverage schemes. They're buying at-home DNA tests, ${ }^{6}$ and extra genetic screening tests for kiddies. ${ }^{7}$ Some insist on cheaper, generic drugs, ${ }^{8}$ whereas others find ways to obtain still-unapproved drugs for compassionate use. ${ }^{9}$ Good shoppers know which malls have MRI machines and which hospitals have "intensivists." 10

Fourth, patients are increasingly unwilling to let third parties (such as employers or government bureaucrats) choose their health insurers. This trend is reflected in the Bush administration's (at this writing tentative) Medicare proposals as well as the proliferation of employer schemes in which patients use a healthcare allowance to purchase their own insurance. ${ }^{11}$ In California, Walgreens is facilitating such choices by selling an HMO report card (soon to be translated into Spanish and Chinese). ${ }^{12}$ 
But the proliferation of opportunities for patient agency does not guarantee that patients will act wisely or responsibly. With partial or unreliable knowledge about medicine's basic scientific and economic realities, and with little experience at integrating healthcare benefits and burdens with competing values, patients seem in some cases to be left without adequate resources to make good decisions. How, then, should newly empowered patients (or even less empowered traditional patients) navigate the increasingly complex and hazardous landscape of contemporary healthcare? What are the characteristics of a wise or savvy patient? Is there such a thing as a virtuous patient? Do patients have particular obligations or responsibilities to healthcare providers, to one another, or to the public? This issue of $C Q$ begins to explore these burgeoning perplexities.

In approaching potential contributors for this project, I left the topic as open-ended as possible-often leaving them with little more than a notice of our focus on "patient ethics." Interestingly, three rather distinct responses are exhibited in the essays. Bruce Waller focuses on whether patients can be held responsible for particular healthcare-related decisions or outcomes. Three other authors (Howard Brody, Kevin Wildes, and Kim Garchar) find abstract notions of the responsible patient less problematic, and focus instead on the nature and scope of patient responsibilities and/or the characteristics of effective, responsible patients. Mark Hall goes a third way, concentrating on the nature and significance of trust-as a foundation for provider-patient relationships and hence for patient ethics as well. ${ }^{13}$ In the remainder of this introductory essay I will critically examine each of these responses.

\section{Is It Possible to Be Responsible for Bad Health Outcomes?}

In certain, mostly Protestant, circles, an informal doctrine of predestination enjoys many adherents. The crux of the doctrine consists of two propositions. First, all of the world's salient events - that is, all things related to salvationare engineered or predetermined by God with no contribution from other parties. Second, all of the world's negative events-that is, all things that impede salvation-are engineered by human beings. In essence, such Christians support what has been called a doctrine of "single predestination": We are saved by Grace alone, but should we be lost, it is our own fault.

Among staunch liberal egalitarians, a parallel but inverse doctrine of single predestination has evolved, holding that (1) all the world's negative outcomesthat is, all instances of poverty, ill health, inertia, superstitious thinking, and other failures to flourish-are determined by impersonal forces such as the natural lottery, the social lottery, or the operation of conservative ideology; and yet (2) all of the world's positive outcomes - things like happiness, creativity, solidarity, equality, world peace, and healthy populations-are victories of human spirit, freedom, and intelligence. In essence, this species of liberal egalitarianism holds that we are lost by the lottery alone. ${ }^{14}$ But when we are saved it is our own doing, and self-congratulation is in order.

The problem with doctrines of single predestination (Christian and liberal egalitarian inclusive) is that they are self-referentially inconsistent and, hence, false. We are either saved or we are not saved. Hence, if our salvation is wholly up to God, then so is our nonsalvation (because everyone God does not save will end up being not saved). And, with respect to any particular object of 
flourishing, we either flourish or we do not flourish. Hence, if the failure to flourish is wholly determined by impersonal forces, then so is flourishing (because every person and every community that does not fail to flourish will flourish).

At first glance, Bruce Waller seems in this issue to be propounding a liberal egalitarian version of single predestination. "Moral responsibility and just deserts are harmful," Waller writes, while holding that autonomy and takecharge responsibility are beneficial. He cites Willard Gaylin, John Hardwig, Walter Glannon, Leon Kass, Alvin H. Moss, Mark Siegler, and others as falling prey to "a common confusion" that patients' take-charge responsibility (in which patients are encouraged to exercise decisional control and active involvement in health-related matters) implies just-deserts responsibility (in which patients are regarded as bearing a degree of accountability for health outcomes relating to their decisions and actions). To the contrary, Waller holds that bad behavior and bad outcomes result from "a causal history that shatters any illusion of fair 'just deserts.' " He cites genetics and environment (or, as many contemporary political theorists dub them, the natural and the social lotteries) as determinants of bad outcomes. But, in an apparent endorsement of single predestination, he nevertheless holds that patients should be encouraged to rise above genetics and environment when it comes to positive outcomes-that they can take charge of their lives and reshape their attitudes and habits toward better ends.

If this is Waller's thesis, then it is Waller and not the others who is shrouded in confusion. As a matter of logic, it is not plausible that bad outcomes are wholly determined by the natural and social lotteries, whereas the avoidance of bad outcomes results from the interaction of natural and social lotteries with other causative factors. If the lotteries are the only factors determining bad outcomes, then bad outcomes will be avoided (and good outcomes achieved) if and only if the lotteries deliver favorably.

But I think that Waller can and should be interpreted more charitably. By endorsing take-charge responsibility, Waller appears to be upholding a psychological thesis - that good things often result when patients experience a feeling of individual control. This thesis is plausible even if (as Waller seems to hold) the sense of control is based on a fiction. His repudiation of just-deserts responsibility, on the other hand, is directed against a metaphysical thesis - the claim that individuals actually do exert a degree of individual control over their lives. ${ }^{15}$ This version of Waller's position is certainly debatable, but it is plausible and worth considering.

Waller offers a number of cogent reasons for his psychological thesisincluding an analysis of empirical studies concerned with the health-related effects of take-charge responsibility. Much of his argument against the metaphysical thesis also focuses on health-related effects-but these are not directly relevant to the point of contention. Even if it is the case that holding people responsible for their actions countervails health promotion (a point that I would not concede based on Waller's data), this fact would not defeat the thesis that individuals are, in some circumstances, responsible for their actions.

His only substantive stab at the metaphysical thesis comes in an analysis of the groundskeeper (let us call her " $G$ "). Though Waller thinks that G can assume take-charge responsibility for preparing the field for tomorrow's match, he contends it is not plausible to assign just-deserts responsibility for good 
results or bad results. Good results might be due to $G$ assigning the work to an assistant, and bad results might be due to unavoidable bad weather. Though this example supports the noncontroversial claim that take-charge responsibility does not always beget just-deserts responsibility, it is far from sufficient for Waller's claim that take-charge responsibility never begets just-deserts responsibility. What about cases in which the weather is good and G doesn't assign the work to someone else? Can $\mathrm{G}$ be relieved of responsibility by claiming that she didn't receive enough energy in the natural lottery?

The weakness of Waller's case is even more evident in his comparison of Albert (the "cognitive miser") with Mohammed (the "eager cognizer"). Waller holds that anyone holding them to just-deserts responsibility must be asserting that causal histories did not shape them, and has descended into an explanatory "fire of mystery." Aside from the obvious rejoinders that causation is itself a persistent mystery, and that our ability to predict human behavior (e.g., suicide) based on antecedent facts is limited, Waller's comments seem susceptible to a graver dictum. He seems to be saying that either (1) bad behavior is entirely determined by the lotteries or (2) it is "miraculously independent" of them. But of course there is a third, very obvious, possibility - that the lotteries are important factors but not the whole story.

So there, in my opinion, is where Waller leaves us-with an interesting and plausible hypothesis, solidly in line with much current liberal egalitarian thinking, but questionable in its attack on just-deserts responsibility.

\section{Asking for Antibiotics and Requesting Assistance in Suicide- The Parameters for Taking Charge}

Brody, Garchar, and Wildes focus on delineating a realm of responsibility for patients as active agents within the patient-physician relationship and in patients' relationships with a larger community interested in healthcare. Ostensibly, then, these three seem to be concerned with take-charge responsibility rather than with what Waller has termed "just-deserts" responsibility. However, there is a critical difference. Each of these thinkers clearly regards take-charge responsibility in ethical terms - as a matter of assuming ethical responsibility rather than, as in Waller's case, simply exercising a healthenhancing prerogative to act or to decide. When take-charge responsibility is utilized in this ethical sense, just-deserts responsibility (or, more generically, "accountability") is implied reciprocally. That is, "responsibility," in the ethical sense, means both (1) accepting a warrant to act or decide ethically and (2) bearing a degree of accountability for one's actions or decisions. Hence, for instance, Wildes argues that "trends that have changed medicine and opened the doors for patient choice have also opened the issue of personal responsibility for one's health."

Brody asks if it is ethical for patients to request antibiotics for common upper respiratory infections. Given the ubiquity of such patient requests, of prescriptions for ineffective antibiotics, and of drug-resistant bacteria emerging due to the overuse of antibiotics, this question seems crucial. Brody begins by contrasting the dominant autonomy-based approach, which tends to the supposition that patients can ask for whatever they want and that it is the clinician's duty to provide it once all the relevant information has been imparted, with the "doctrine of futility," which specifies that clinicians should never provide 
clearly ineffective interventions. Though Brody does not explore the autonomy approach in detail, it bears a striking resemblance to Waller's endorsement of take-charge responsibility. In each case, patients are endowed with decisional prerogatives - sans ethical accountability.

But Brody endorses a third approach. He carves out a collaborative account of evidence-based clinical deliberation (amending the largely physiciancentered account of evidence-based medicine that currently holds sway). Patients, in his view, "are invited to determine the clinical outcomes that matter most." Hence, it is up to the patient considering estrogen-progestin products to decide whether avoiding certain risks of heart disease and cancer are more or less important than relieving postmenopausal symptoms. Yet the prerogative to articulate individual goals of treatment does not give the patient carte blanche. Adequately informed and capable patients have an ethical obligation to undertake treatment decisions responsibly - that is, in a manner that respects (1) the tenets of good evidence that partially define competent medical practice and (2) the fair distribution of scarce medical resources within the larger community of which the patient is a part. On the basis of these two factors, Brody argues that, for the most part, patients have an ethical obligation to refrain from requesting antibiotics for upper respiratory infections. Exceptions to this dictum occur, as Brody elegantly argues, due to inherent limitations of the population-based approach in evidence-based medical reasoning. In some circumstances, there may be good reason to believe that specific patients will defy statistical trends and experience benefit from antibiotics prescribed for upper respiratory infections.

Brody's approach is commendable in its subtle understanding of evidencebased reasoning, its endeavor to retain the centrality of the patient-physician relationship while locating it within the context of a larger civil society, and in its palpable relevance to actual clinical practice. Much more could be said, however, about the sources of patients' ethical obligations. Brody might add-as Garchar does in her assessment of Josiah Royce's ethics - that patients have an ethical obligation to carve a coherent personal identity through loyalty to causes greater than their own isolated impulses. ${ }^{16}$ This duty of self-governance is at once both personal and social. Not only should patients attend to fairness in the distribution of medical resources (a slippery issue at best, given the contention about distributive justice), but, more broadly, patients should cultivate a life plan that joins them to other actual and potential loyalists, while respecting the loyalties of individuals with diverging moral visions. Such patient obligations are hardly a proper object of scrutiny or judgment by clinicians-but within the realm of an ethics explicitly for patients, they seem clearly relevant.

Garchar employs this Roycean ethics of loyalty to defend the practice of physician-assisted suicide. Garchar, writing from the University of Oregon, observes that in Oregon the majority of requests for suicide are based on concerns about losing autonomy or losing the ability to participate in the activities that make life enjoyable. In a departure from typical communitarian reasoning, she portrays the concern with autonomy as a "common communal ideal," rather than as a form of selfish independence. She goes on to argue that, in some cases, this ideal is such a dominant focus of the life plan that assisted suicide (to avoid the loss of autonomy) contributes a salient individual and social meaning to dying. Critics might respond (as I have in previous essays) that autonomy-based arguments for assisted suicide neglect the degree to 
which this role undermines clinicians' professional values and the trust that is built upon them. However, Garchar offers a powerful rejoinder-that currently physicians have a virtual monopoly on the means for assisting suicide, and hence a prima facie obligation to make these available in cases where suicide may be morally permissible. To buttress her case, I believe that Garchar needs to tell us more about the operation of autonomy as a communal ideal, and about how moral communities are made to flourish (or suffer) when their members opt for assisted suicide. But her essay seems a good start.

Wildes addresses medicine's familiar, ongoing crisis - in which new technologies beget a proliferation of opportunities and choices while moral pluralism and a residuum of debilitated medical professionalism undermine consensus about how individuals and communities should navigate them. Our understanding of patients is a Rosetta Stone, Wildes argues, for deciphering the underlying medical worldviews that compete for preeminence within this moral melee: "One cannot talk about patients in isolation from the other players in healthcare. One's understanding of the patient will be embedded in one's understanding of the purpose of medicine."

Hence, Wildes holds that the traditional conception of the patient is wedded to a traditional account of the nature and purpose of medicine. Here the patient is essentially a passive sufferer - afflicted by debilitating illness and dependent on the expertise and goodwill of the physician. Wildes holds that, although patients may be beholden to follow doctors' orders, "[ $t$ ]here is no basis, in this model, to establish a dimension of responsibility on the part of the patient for his or her own health."

The traditional model has been undermined, however, by the aforementioned technological explosion, the recognition of ethical pluralism, and a patient rights ideology that stresses the decisional prerogative of competent patients. In addition, we might add that a shift toward chronic disease management and preventive medicine, as well as the enhancement of opportunities for patient participation in the economics of healthcare, have eroded the image of the patient as a passive victim of acute illness.

Several alternatives to the traditional model emerge. Wildes rejects consumer, contractual, and client models because they tend to distill out essential humanistic and communal elements of healthcare, neglecting the degree to which patients remain vulnerable and dependent. The "friendship model," on the other hand, is too much of a stretch-overstating the likelihood that patients and clinicians will share their time, understandings, and moral values. Wildes' suggestion is that we adopt a "partnership model" of the patient's role. In this view, patients "coauthor" clinical goals and decisions in a collaborative relationship with clinicians that parallels Brody's account of the clinical relationship. Patients inherit moral obligations of honesty, cooperation, stewardship, and citizenship, each described in considerable detail by Wildes. Echoing Garchar, Wildes emphasizes the manner in which patients and patientphysician dyads need to interpret their decisions within a (perhaps thin, but nevertheless substantive) nexus of societal values.

In essence, Wildes has attempted to accommodate the emphasis on patient participation to the existential reality of vulnerability and dependence. An important underlying dynamic seems to be the old issue of trust. Patients cannot be viewed as simple economic or decisional units because their dependence necessitates the cultivation of a trusting relationship with beneficent 
partners. This consideration advances the hermeneutic toward our final contributor-Mark Hall-and his discussion of the role of trust in healthcare ethics, law, and public policy.

\section{The Importance of Trust}

Hall distinguishes three sometimes overlapping attitudes or stances assumed by health policymakers, providers, critics, and patients toward trust. In the predicated stance, trust is viewed as an antecedent, empirical fact. Here trustbased deliberation focuses on ethical responsibilities that issue from the obvious and inevitable fact that patients trust their physicians. From the predicated stance, the concern is with maintaining trustworthiness at a level commensurate with actual trust. This stance, as Hall observes, is dominant in traditional models of the patient-physician relationship, where the vulnerability and passivity of the patient is emphasized. In her debilitated, ill-informed, and dependent state, the patient is viewed as having no viable option other than to trust the physician.

The supportive stance, on the other hand, views trust as a crucial but precarious feature of patient-clinician relationships. Here the emphasis is on cultivating conditions that "support, enhance, or restore trust." In the aftermath of highly publicized mishaps such as Tuskegee and the Gelsinger affair, one could cite the medical research establishment as an institution needing such support. On this basis, we might view the contemporary Institutional Review Board as not so much holding researchers accountable to the public's trust, but as enacting measures that will repair and maintain damaged trust.

Finally there is the skeptical stance. Hall writes: "This stance assumes that trust is diminished and cannot be effectively maintained, and therefore looks for substitute means to maintain medical relationships." He cites the regulation of managed care organizations as typically involving this stance. He also notes that "distrust can help establish trust if initial experiences are positive and verification eventually proves to be unnecessary." This latter eventuality, however, seems more in line with the supportive stance, since, as Hall observes, "true trust is restored only if verification is, for the most part, eventually abandoned."

Though Hall is concerned more with describing each of these stances and their rationales than with prescribing the optimum homeostasis between them, his elegant analysis of their respective contributions and limitations forcefully commends an integrative approach. Each stance is important in certain circumstances, but each becomes a liability when it is emphasized to the exclusion of others. He cites evidence, for instance, that patients' levels of trust for physicians remain high, even in the face of physician failures or other countervailing factors, but also argues that it would be unreasonable to expect physicians, hospitals, and health plans to "perform at the level of actual trust." Likewise, he argues that proponents of the supportive stance often underestimate the resilience of trust-citing the lack of empirical evidence that assisted-suicide prohibitions, confidentiality laws, privacy laws, and the elimination of physician conflicts of interest are necessary to maintain trust. Hall also warns that efforts to support trust can paradoxically weaken it (by "conveying to the public an attitude of distrust and by reducing medical actors' motivations to behave in a trustworthy fashion"). Yet he concedes that the importance and 
intensity of trust beget a situation where serious betrayals of trust can be particularly explosive and almost impossible to remedy. Because it is difficult to forecast such events, Hall warns that "those who advocate supportive legal measures should not have to bear the burden of proving their case empirically."

\section{Conclusion}

In supporting an open-ended, collaborative relationship between clinicians and patients, Brody, Garchar, and Wildes seem motivated, at least in part, to accommodate the nuances of trust. An extreme predicated stance, where physicians are viewed as virtually superhuman healers, is unrealistic-especially given current levels of ethical pluralism and the medical and financial alternatives that patients and their providers must navigate. Yet, as Wildes particularly underscores, an austere consumerist model would lead us too far afield in the other direction - toward the skeptical stance and an impoverished patientclinician relationship where the intrinsic and instrumental benefits of trust are distilled nearly out of existence. Brody's collaborative evidence-based model, Garchar's socially informed loyalty model, and Wildes' partnership model all support trust by portraying patients and clinicians cooperatively. Yet they avoid unreasonable, undue, or counterproductive patient dependence (and support ethical self-governance) by emphasizing that patients must ultimately trust themselves to make certain critical decisions. This self-reliance, it seems, carries a degree of ethical accountability.

Waller repudiates ethical accountability, because he thinks (1) it undermines the goals of medicine by producing ill health, and (2) it is refuted by behavioral science. Though he offers little warrant for point 2, it may be possible to reinterpret point 1 in view of our discussion of trust. To wit, it may be the case (contrary to Waller) that patients actually bear a degree of ethical accountability for their health-outcome-producing behavior. Yet it may also be the case (in accordance with Waller) that clinicians, other providers, and (perhaps to a lesser extent) health policymakers should generally refrain from passing judgment on illness-producing behavior. Judgment should be withheld, not because patients are never accountable, but because clinicians and other healthcare providers are supposed to be partners, not critics. This quasi-fiduciary partnership relationship functions properly only when clinicians focus on patient needs and goals, and only when patients can approach the clinician honestly and openly-disclosing even morally blameworthy behaviors without fear of reprisal or adverse rationing decisions.

\section{Notes}

1. Landro L. Health-care reformers regroup in Jackson Hole. Wall Street Journal 2002 Oct 2;Sect. D:3.

2. Rundle RL. Healthcare providers let patients view records online. Wall Street Journal 2002 Jun 25;Sect. B:1,5.

3. To view the matter more cynically, perhaps the New Jersey lady managed to add unnecessary and dangerous antibiotics to her father's care by harassing his physician about unimportant temperature fluctuations.

4. Chin T. New survey finds fewer patients searching online. American Medical News 2003 April 14:17. Estimations of the prominence of this trend vary. A recent study by the Center for 


\section{Guest Editorial}

Studying Health System Change found only 38\% of adults seeking health information from a source other than their physician, and less than half of these used the Internet. Other organizations, such as the Pew Internet \& American Life Project and Harris Interactive found much higher rates of Internet use by patients.

5. Parker-Pope T. Research for hire: Firms help patients find latest cures for chronic illnesses. Wall Street Journal 2002 Nov 26;Sect. D:1.

6. Pearson H. At-home DNA tests are here. Wall Street Journal 2002 Jun 25;Sect. D:6.

7. Marcus AD. Anxious parents pay labs for extra tests on newborns. Wall Street Journal 2002 Nov 20;Sect. D:1.

8. Hensley S. How new generics can cut your drug bills. Wall Street Journal 2002 Jun 6;Sect. D:1,3.

9. Fuhrmans V. How to get new-but unapproved-drugs. Wall Street Journal 2002 Dec 5;Sect. $\mathrm{D}: 1,3$.

10. Landro L. Improving your chances in intensive care. Wall Street Journal 2002 Nov 21;Sect. D:1,3.

11. Herzlinger R. Let's put consumers in charge of health care. Harvard Business Review 2002;80:44-55.

12. Benson M. Coming soon at Walgreens: HMO ratings. Wall Street Journal 2002 Sep 19;Sect. D:1.

13. Hall's book, Making Medical Spending Decisions. New York: Oxford University Press, 1997, contains a pioneering treatment (pp. 15-61) of patient spending decisions.

14. John Rawls, though not strictly a single predestinarian, is something of a founding father for the movement-holding (Rawls J. A Theory of Justice. Cambridge, Mass.: Belknap Press of Harvard University Press; 1971) that "the notion of desert" does not apply in cases where persons better their condition through "good character" (p. 104) or "effort" (p. 312), since these effects result largely from the social and natural lotteries.

15. In essence, Waller's metaphysical thesis is that humans are not free. He justifies this claim by an appeal to empirical biological science. However, the claim that biological science repudiates freedom-either by stipulation or as a well-founded inductive inference-is not straightforward. For an account of freedom as an emergent biological property, see Tallis, RC. Human freedom as a reality-producing illusion. The Monist 2003;86(2):200-19.

16. Garchar writes: "we assume that persons are not only responsible for their own actions, but also, generally speaking, the goals associated with those actions." 